\title{
A comparison of the excretion rate of endogenous purine derivatives in the urine of Bos indicus and Bos taurus steers
}

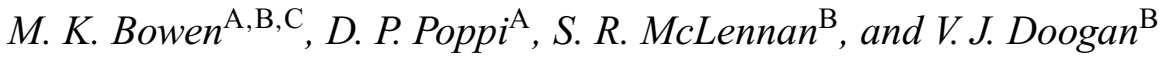

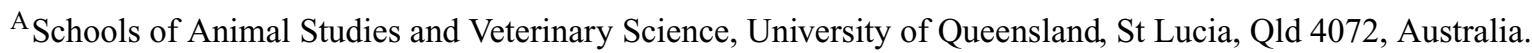 \\ ${ }^{B}$ Animal Science, Department of Primary Industries and Fisheries, Animal Research Institute, \\ Moorooka, Qld 4105, Australia. \\ ${ }^{\mathrm{C}}$ Corresponding author. Email: maree.bowen@dpi.qld.gov.au
}

\begin{abstract}
Estimates of microbial crude protein (MCP) production by ruminants, using a method based on the excretion of purine derivatives in urine, require an estimate of the excretion of endogenous purine derivatives (PD) by the animal. Current methods allocate a single value to all cattle. An experiment was carried out to compare the endogenous PD excretion in Bos taurus and high-content $B$. indicus (hereafter, $B$. indicus) cattle. Five Holstein-Friesian (B. taurus) and 5 Brahman ( $>75 \%$ B. indicus) steers (mean liveweight $326 \pm 3.0 \mathrm{~kg}$ ) were used in a fasting study. Steers were fed a low-quality buffel grass (Cenchrus ciliaris; $59.4 \mathrm{~g}$ crude protein/kg dry matter) hay at estimated maintenance requirements for 19 days, after which hay intake was incrementally reduced for 2 days and the steers were fasted for 7 days. The excretion of PD in urine was measured daily for the last 6 days of the fasting period and the mean represented the daily endogenous PD excretion. Excretion of endogenous PD in the urine of $B$. indicus steers was less than half that of the B. taurus steers $\left(190 \mu \mathrm{mol} / \mathrm{kg} \mathrm{W}^{0.75}\right.$.day $v .414 \mu \mathrm{mol} / \mathrm{kg} \mathrm{W}^{0.75}$.day; combined s.e. $37.2 \mu \mathrm{mol} / \mathrm{kg} \mathrm{W}^{0.75}$.day; $P<0.001$ ). It was concluded that the use of a single value for endogenous PD excretion is inappropriate for use in MCP estimations and that subspecies-specific values would improve precision.
\end{abstract}

Additional keywords: rumen microbial protein, cattle.

\section{Introduction}

The method involving measurement of the excretion of purine derivatives (PD) in urine, for estimating microbial crude protein (MCP) flow to the small intestines in ruminants, is based on the principle that the urinary PD originate largely from the degradation of absorbed microbial nucleic acids (McAllan and Smith 1973; Verbic et al. 1990; Chen and Gomes 1995). However, PD in the urine also originate from tissue nucleic acid turnover and these endogenous PD need to be accounted for in the determination of the MCP production by this technique.

In the equation used widely for calculating MCP flow in cattle, which was developed by Verbic et al. (1990) and revised by Chen and Gomes (1995), a constant value for endogenous excretion of PD in the urine of cattle is assumed, viz. $385 \mu \mathrm{mol} / \mathrm{kg} \mathrm{W}^{0.75}$.day. This value was derived using Bos taurus cattle but several studies have shown that purebred and high-content $B$. indicus cattle may have lower rates of excretion of endogenous PD (Osuji et al. 1996; Liang et al. 1999; Pimpa et al. 2001; Ojeda et al. 2005). However, the comparison of cattle subspecies in this regard has been confounded by the technique used to estimate endogenous PD excretion. Most experiments with $B$. taurus cattle have used the technique of total nourishment of animals by intragastric infusion (Fujihara et al. 1987; Chen et al. 1990; Verbic et al. 1990), whereas those with B. indicus cattle have used a technique involving the prolonged fasting of animals with associated measurement of urinary PD excretion (Osuji et al. 1996; Liang et al. 1999; Ojeda et al. 2005).

In our experiment the endogenous excretion of PD in the urine was compared between $B$. taurus and high-content $B$. indicus (hereafter B. indicus) steers using the fasting technique. A brief report that gives some aspects of these data has appeared elsewhere (Bowen et al. 2003).

\section{Materials and methods}

Animals and management

Five Holstein-Friesian (B. taurus) and 5 Brahman $(>75 \%$ B. indicus $)$ steers, 16 months of age with initial average liveweights of $323 \pm 3.8 \mathrm{~kg}$ and $329 \pm 4.7 \mathrm{~kg}$, respectively, were used. The steers were treated with moxidectin (Cydectin, Fort Dodge Australia Pty Ltd) to control internal and external parasites at the commencement of the experiment. The experiment was run at the Mt Cotton Research Unit of the University of Queensland and was approved by the University of Queensland Animal Ethics Committee. 
The experiment consisted of a 14-day preliminary feeding period in individual, concrete-floor pens and a 14-day sampling period in metabolism crates. Steers were allocated to pens and crates in a completely randomised layout. The steers were fed a low-quality tropical-grass hay (buffel grass, Cenchrus ciliaris). Intake was fixed at a level equivalent to metabolisable energy (ME) maintenance requirements (calculated according to SCA (1990); mean: $41.8 \mathrm{MJ} /$ steer.day) during the preliminary feeding period and for the first 5 days of the sampling period. Over Days 6, 7, and 8 of the sampling period the feed intake of the steers was reduced to $60 \%, 30 \%$, and $0 \%$ of ME maintenance requirements, respectively, with fasting continuing for a total of 7 days. The steers had free access to drinking water at all times.

\section{Experimental procedures}

For each steer, hay intake was recorded over the first 7 days, and daily faecal output over the duration of the sampling period. Organic matter digestibility (OMD) of the diet was determined for Days 1-5. During the sampling period, total urine was collected daily into bins containing a sufficient quantity of $20 \%$ sulfuric acid so that the final $\mathrm{pH}$ of urine was kept below 3 . Urine was weighed and a $10 \%$ daily subsample was kept and bulked for each steer over Days 1-5. These samples were stored frozen $\left(-20^{\circ} \mathrm{C}\right)$ and later thawed, mixed thoroughly, subsampled, and diluted 1 in 10 with $0.1 \mathrm{~m}$ ammonium phosphate $\left(\mathrm{NH}_{4} \mathrm{H}_{2} \mathrm{PO}_{4}\right)$ buffer. The buffered subsamples were frozen prior to analysis for PD concentration. Over the final 9 days of the sampling period the urine for each steer was not bulked but was subsampled and diluted, as described above, daily. The steers were weighed at the beginning and end of the sampling period.

\section{Analytical procedures}

Hay samples, 1-mm ground, were analysed for total nitrogen (N) concentration by a combustion method (Sweeney 1989) using an ELEMENTAR RapidN combustion analyser (ELEMENTAR ANALYSENSYSTEME GmbH, Germany). Ash-free neutral detergent fibre (NDFom) and ash-free acid detergent fibre (ADFom) were determined by the methods of Van Soest and Wine (1967) and Van Soest (1963), respectively, adapted for the Fibretec 2021 Fibrecap system developed by FOSS TECATOR (FOSS TECATOR 2002a, 2002b).

Acidified and buffered urine samples were thawed, filtered with $0.2-\mu \mathrm{m}$ Alltech cellulose nitrate or acetate membrane filter followed by a C18, 300-mg filter, and analysed for PD concentration using a highperformance liquid chromatograph according to the method outlined by Balcells et al. (1992).

\section{Calculations}

The endogenous production of PD was determined as the total PD (sum of allantoin, uric acid, hypoxanthine, and xanthine) excretion by steers over Days 9-14 of the sampling period (see Statistical analyses). The flow of MCP to the intestines of steers for the first 5 days of the sampling period was calculated using the equations proposed by Chen and Gomes (1995). Calculations were made using their published value for endogenous PD excretion $\left(385 \mu \mathrm{mol} / \mathrm{kg} \mathrm{W}^{0.75}\right.$.day) and also by using the value derived in our experiment during the 9-14-day sampling period, for each subspecies of cattle.

\section{Statistical analyses}

The statistical package, Genstat for Windows, 6th edn (Genstat Committee 2000), was used for all statistical analyses. All values are given as mean \pm s.e. unless otherwise indicated. An unpaired $t$-test was used to compare the 2 subspecies of cattle for the variables OMD, PD excretion, MCP flow, and efficiency of microbial protein synthesis (EMPS) during the first 5 days of the sampling period.
PD excretion during the fasting period, Days 9-14, was analysed using a linear mixed model fitted using restricted maximum likelihood (REML). The full model included the fixed effects time and subspecies, and their interaction, with the residual variance, steer.time, as the random effect. Time had 6 levels, the Days 9-14, and subspecies had 2 levels, $B$. taurus and B. indicus. Day 8 was not included in the analysis since large PD excretion values for several steers on Day 8 indicated that these steers had not yet reached their endogenous PD level. To account for possible correlation over time within steers, the covariance structure of the residual variance was investigated. Likelihood ratio tests were used to compare competing random models for the residual variance, resulting in the selection of an unstructured covariance model. Significance of fixed effects was then assessed using Wald tests. Since the interaction between subspecies and time was not significant $(P=0.07)$ it was removed from the model. For significant fixed effects, approximate pairwise comparisons of means were made at $P=0.05$.

\section{Results}

The buffel grass hay fed to steers during the first 7 days of the sampling period had a composition of organic matter (OM), NDFom, ADFom, and crude protein (CP) of 895, 729, 441 , and $59.4 \mathrm{~g} / \mathrm{kg}$ dry matter (DM), respectively. The OMD averaged $580 \pm 4.3 \mathrm{~g} / \mathrm{kg}$ and was not significantly different $(P=0.72)$ between subspecies of cattle.

The faecal DM output declined rapidly over Days 7 and 8 of the sampling period and then more slowly over the last 6 days of the 7-day fasting period (Fig. 1). Faecal output had decreased to an average of $132 \pm 28.4 \mathrm{~g} \mathrm{DM} /$ day by Day 7 of fasting. B. taurus and B. indicus steers had similar liveweight loss over the 14-day sampling period, with liveweights declining by $48 \pm 3.4 \mathrm{~kg}$ and $44 \pm 2.7 \mathrm{~kg}$, respectively.

Mean excretion of PD during the first 5 days of the sampling period, when the steers were fed

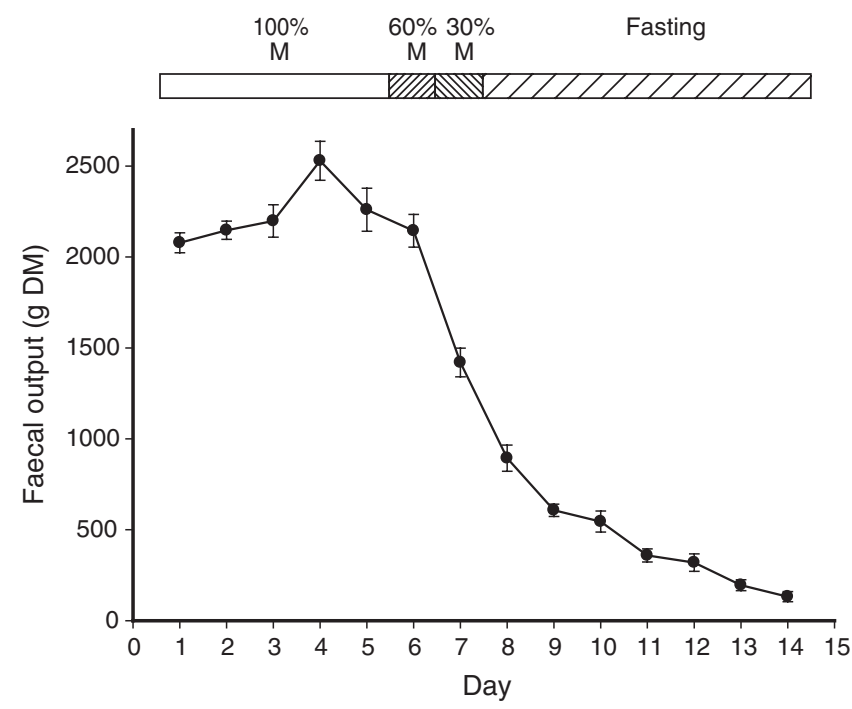

Fig. 1. Daily faecal output by steers during the sampling period [values are the mean of all steers from both subspecies \pm s.e.; the intake by steers is shown in the bar graph as a percentage of estimated ME maintenance requirements $(\mathrm{M})$ ]. 
at maintenance, averaged $1059.5 \pm 136.04$ and $840.8 \pm 77.52 \mu \mathrm{mol} / \mathrm{kg} \mathrm{W}^{0.75}$.day for $B$. taurus and $B$. indicus steers, respectively, with the difference not being significant $(P=0.20)$. During the period of reducing intake (Days 6 and 7) the excretion of PD for both groups of steers first increased sharply, then declined sharply by Day 9, remaining relatively constant to the end of the fasting period (Fig. 2). For Days 9-14, when steers were fasted, mean excretion of PD (assumed to be endogenous excretion) for $B$. taurus steers was more than double that for their B. indicus counterparts (414.0 v. 189.8 (combined s.e. 37.2$) \mu \mathrm{mol} / \mathrm{kg} \mathrm{W}^{0.75}$.day; $\left.P<0.001\right)$. These values were considered to represent endogenous PD excretion, assuming that urinary PD coming from intestinal absorption of purines represented only a minor proportion. There was no significant difference in PD excretion between each of Days 9-12 or Day 14 . However, PD excretion for Day 13 was significantly lower $(P<0.05)$ than that for all other days except Day 12 . Allantoin was the major PD present in the urine and changes in its concentration were the major influence on the decrease in PD excretion with fasting (Fig. 3). Negligible amounts of hypoxanthine and xanthine were detected in the urine of either subspecies group. The mean excretion of individual PD over the first 5 days of sampling when steers were fed at maintenance was: $869.9 \pm 71.31,80.2 \pm 11.72,0 \pm 0$, and $0.1 \pm 0.07 \mu \mathrm{mol} / \mathrm{kg} \mathrm{W}^{0.75}$.day for allantoin, uric acid, hypoxanthine, and xanthine, respectively.

\section{Discussion}

This experiment has provided the first true comparison of $B$. taurus and $B$. indicus cattle in terms of their endogenous excretion of $\mathrm{PD}$ and indicates a 2 -fold difference between

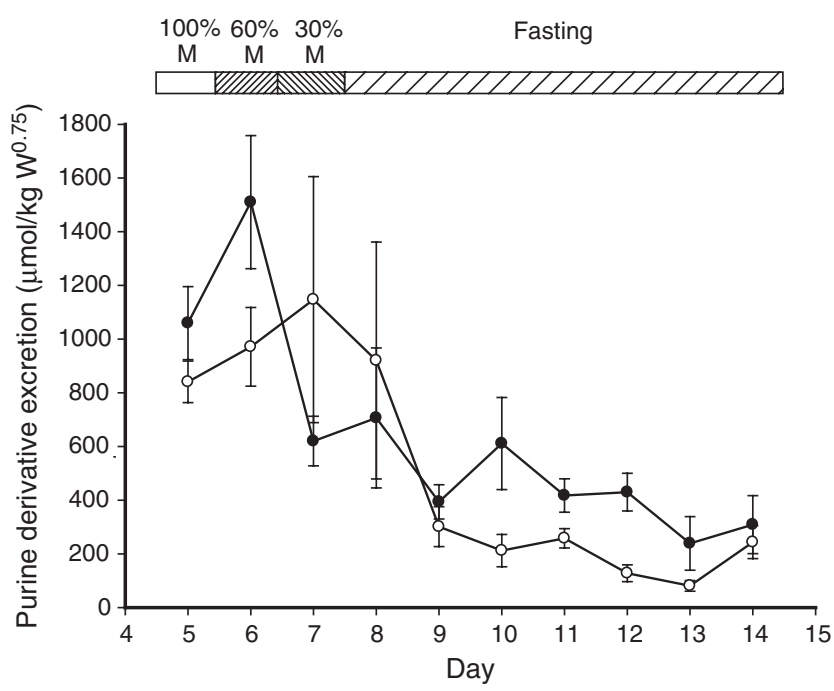

Fig. 2. Daily excretion of purine derivatives in urine of B. taurus $(\bullet)$ and $B$. indicus $(O)$ steers during the sampling period [mean \pm s.e.; the intake by steers is shown in the bar graph as a percentage of estimated $\mathrm{ME}$ maintenance requirements $(\mathrm{M})]$. subspecies in this parameter, although large standard errors were recorded. This indicates that the use of a single value for endogenous PD excretion (e.g. $385 \mu \mathrm{mol} / \mathrm{kg} \mathrm{W}^{0.75}$.day), for cattle of different subspecies, is inappropriate.

The endogenous excretion of PD we have measured for Holstein-Friesian steers, using the fasting technique, falls within the large range of values reported by other researchers for $B$. taurus cattle using a number of other techniques (mean of all values: $466 \pm 36.0 \mu \mathrm{mol} / \mathrm{kg} \mathrm{W}^{0.75}$.day). These included the intragastric infusion method (428-514 $\mu \mathrm{mol} / \mathrm{kg} \mathrm{W}^{0.75}$.day; Fujihara et al. 1987; Chen et al. 1990; Verbic et al. 1990), the rumen emptying technique $\left(560 \mu \mathrm{mol} / \mathrm{kg} \mathrm{W}^{0.75}\right.$.day; Giesecke et al. 1993), the extrapolation of infusion/excretion regression relationships to zero purine input $\left(531 \mu \mathrm{mol} / \mathrm{kg} \mathrm{W}^{0.75}\right.$.day; Beckers and Thewis 1994), and the isotopic labelling of exogenous purine bases (236 and $512 \mu \mathrm{mol} / \mathrm{kg} \mathrm{W}^{0.75}$.day; Orellana Boero et al. 2001; Gonzalez-Ronquillo et al. 2003). It is also similar to the value used by Chen and Gomes (1995; $385 \mu \mathrm{mol} / \mathrm{kg} \mathrm{W}^{0.75}$.day), which was based on the mean of all measurements made in the laboratory of Verbic et al. (1990) with adjustment downwards of 0.22 for the proportion of exogenous purines salvaged. This latter value was also estimated by Verbic et al. (1990) from the abomasal infusion of microbial extract (Pruteen), and interpreted as utilisation of exogenous purines in the intestinal mucosa. Unfortunately, there appear to be no published values for endogenous PD excretion in B. taurus cattle, which have been obtained using the fasting technique.

Similarly, the value measured in the present experiment for Brahman steers falls within the large range of values for

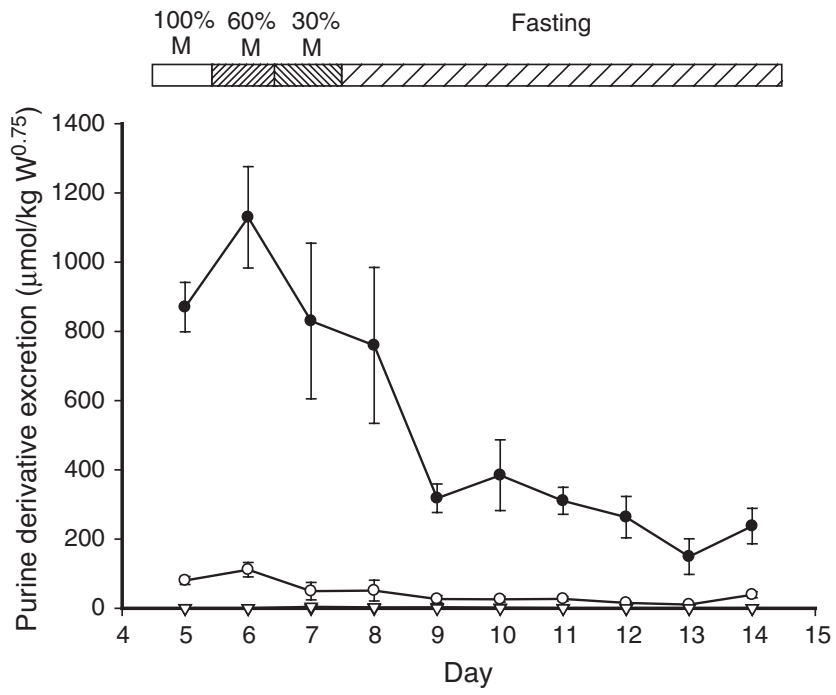

Fig. 3. Daily excretion of allantoin (๑), uric acid (O), xanthine $(\boldsymbol{\nabla})$ and hypoxanthine $(\nabla)$ in urine over the sampling period [values are the mean of all steers from both subspecies \pm s.e.; the intake by steers is shown in the bar graph as a percentage of estimated ME maintenance requirements $(\mathrm{M})]$. 
endogenous PD excretion for $B$. indicus-content cattle (mean of all values: $219 \pm 28.2 \mu \mathrm{mol} / \mathrm{kg} \mathrm{W}^{0.75}$.day). Published values for $B$. indicus-content cattle included 108 and 172 (Osuji et al. 1996), 275 (Liang et al. 1999), and $277 \mu \mathrm{mol} / \mathrm{kg} \mathrm{W}^{0.75}$.day (Ojeda et al. 2005) using the fasting method, and $147 \mu \mathrm{mol} / \mathrm{kg} \mathrm{W}^{0.75}$.day (Pimpa et al. 2001) using the excretion curve after purine infusion.

However, an important consideration is the effect that the proportion of $B$. indicus content in crossbred cattle has upon endogenous $\mathrm{PD}$ excretion. In various experiments studying $B$. indicus $\times B$. taurus cattle, the endogenous $\mathrm{PD}$ excretion for cattle with lower $B$. indicus content, for instance $3 / 8$ and 1/2 B. indicus content (Osuji et al. 1996; Ojeda et al. 2005), was found to be in the same range as for purebred $B$. indicus cattle. This suggests that the endogenous PD excretion for $B$. indicus $\times B$. taurus cattle is more closely aligned to the $B$. indicus than the $B$. taurus subspecies.

The validity of the subspecies comparison in the present experiment was supported by recordings of similar values for OMD and liveweight loss, and similar patterns of both faecal DM output and urinary PD excretion for the 2 subspecies over the sampling period. This indicated that subspecies differences in factors such as diet digestibility, or rate of liveweight loss with fasting, did not confound the betweensubspecies comparison of endogenous PD excretion when the steers were fasted.

It is significant that the fasting technique generally gave similar results to those reported using other methods despite the possibility that nutritional restriction may alter metabolic activity or the rate of degradation of tissue nucleic acids, compared with fully fed animals. There has also been speculation (Osuji et al. 1996; Belenguer et al. 2002) that the duodenal flow of microbe-derived purine bases may not be completely discontinued during the period of fasting and thus may contribute to urinary PD excretion, which is otherwise assumed to be solely endogenous in origin. Although no direct evidence was obtained in this experiment to show that this was not the case, faecal output declined rapidly with food restriction to reach negligible values by Day 7 of fasting. This indicated that the majority of residual material in the reticulo-rumen had been voided and therefore would have made negligible contribution to the total urinary PD output.

Table 1 summarises the estimates of MCP flow and EMPS in cattle, calculated using either the endogenous value for PD excretion proposed by Chen and Gomes (1995), i.e. $385 \mu \mathrm{mol} / \mathrm{kg} \mathrm{W}^{0.75}$.day, or those values determined in our study. The application of the endogenous PD excretion values measured in the present experiment brought the estimates of MCP flow and EMPS much closer together for the 2 subspecies of cattle than occurred when the constant proposed by Chen and Gomes (1995) was used. Using the latter to calculate MCP flow suggests that $B$. indicus cattle have a lower, although not significantly so in this study, MCP flow and EMPS than B. taurus cattle consuming the same
Table 1. Microbial crude protein (MCP) flow and efficiency of MCP synthesis (EMPS) estimated using the values for endogenous purine derivative excretion proposed by Chen and Gomes (1995) for all cattle $\left(385 \mu \mathrm{mol} / \mathrm{kg} \mathrm{W}^{0.75}\right.$.day) or those determined in our experiment for individual cattle subspecies

Results are presented as mean \pm s.e.; DOMI, digestible organic matter intake

\begin{tabular}{lccc}
\hline & B. taurus & B. indicus & $P$ \\
\hline \multicolumn{4}{c}{ Chen and Gomes (1995) } \\
MCP flow (g/day) & $274 \pm 55.3$ & $189 \pm 34.4$ & 0.23 \\
EMPS (g MCP/kg DOMI) & $98 \pm 20.1$ & $78 \pm 12.7$ & 0.42 \\
& This study & & \\
MCP flow (g/day) & $262 \pm 55.3$ & $269 \pm 35.2$ & 0.91 \\
EMPS (g MCP/kg DOMI) & $94 \pm 20.1$ & $112 \pm 12.4$ & 0.47 \\
\hline
\end{tabular}

forage. By contrast, the results of our study suggest that MCP production and EMPS are not significantly different for $B$. taurus and B. indicus cattle consuming a low-quality tropical forage.

The reason for the low endogenous PD excretion in $B$. indicus cattle is unclear. The lower values for endogenous PD excretion in B. indicus cattle, compared with $B$. taurus cattle, could result from a lower xanthine oxidase activity in the former. A high activity of xanthine oxidase prevents salvage of a significant proportion of endogenous PD by causing the diversion of hypoxanthine from the salvage cycle to form xanthine, and then uric acid and allantoin (Chen et al. 1990), neither of which can be incorporated into tissue nucleic acids. Ojeda et al. (2005) made measurements of xanthine oxidase activity in $B$. indicus cattle and found that, compared with reports for B. taurus cattle (Chen et al. 1990), cattle with $1 / 2$ and $5 / 8 \mathrm{~B}$. indicus content had lower activity of xanthine oxidase in the plasma and duodenum but similar activity in the liver. However, if $B$. indicus cattle do have a lower overall xanthine oxidase activity than B. taurus cattle, higher concentrations of xanthine and hypoxanthine would be expected in the urine, as occurs with sheep and goats which have low xanthine oxidase in most tissues and none in the blood (Chen et al. 1990; Belenguer et al. 2002). On the contrary, in the present experiment and in others using B. indicus-content cattle (Osuji et al. 1996; Liang et al. 1999; Pimpa et al. 2001; Ojeda et al.2005), allantoin has been found to be the major component of total urinary PD, with negligible amounts of xanthine and hypoxanthine, similar to that found for B. taurus cattle.

An alternative hypothesis for the low endogenous PD excretion of B. indicus cattle has been offered by Osuji et al. (1996). They suggested that as part of the evolution of $B$. indicus cattle to conserve $\mathrm{N}$ they have an enhanced ability to dispose of purine metabolites via non-renal routes, e.g. by increased recycling to the rumen. However, the validity of this theory is challenged by the results of other researchers who found that the recovery of supplied exogenous purine 
bases in the urine was 0.82 for $5 / 8 \mathrm{~B}$. indicus-content cattle (Ojeda et al. 2005) and 0.85 for Kedah-Kelantan (pure bred $B$. indicus) cattle (Pimpa et al. 2001), and thus similar to that found for European cattle (0.85, Verbic et al. 1990; 0.86, Vagnoni et al. 1997; and 0.84, Orellana Boero et al. 2001).

\section{Conclusions}

Whilst the current experiment used only small group sizes to represent the 2 subspecies, the large differences in mean endogenous PD excretion rate between them, supported by previous trends, indicate the inappropriateness of using a single value for all cattle and suggest improved precision in estimating MCP production if between-genotype differences are recognised. Furthermore, our findings suggest that previously published estimates of MCP production for $B$. indicus cattle need to be re-evaluated. The large betweenanimal differences related to our measurements highlight the risks associated with use of the method for comparing individual animals and indicate its use be directed mainly to group comparisons.

\section{Acknowledgments}

This study was mainly funded by the Department of Primary Industries and Fisheries, Queensland, which provided postgraduate support for M. K. Bowen. M. K. Bowen was also in receipt of an Australian Government Postgraduate Research Award. The analysis of purine derivatives by M. Nielsen and the technical assistance of 'Mt Cotton' staff are appreciated, as well as veterinary supervision of the cattle by J. Gibbs.

\section{References}

Balcells J, Guada JA, Pieró JM, Parker DS (1992) Simultaneous determination of allantoin and oxypurines in biological fluids by high-performance liquid chromatography. Journal of Chromatography 575, 153-157.

Beckers Y, Thewis A (1994) Excretion of purine derivatives in urine of Belgian Blue bulls following duodenal infusion of purines from Torula yeast. Proceedings of the Society of Nutrition and Physiology 3, 235.

Belenguer A, Yanez D, Balcells J, Ozdemir Baber NH, Gonzalez Ronquillo M (2002) Urinary excretion of purine derivatives and prediction of rumen microbial outflow in goats. Livestock Production Science 77, 127-135. doi: 10.1016/S0301-6226(02)00081-7

Bowen MK, McCosker K, McLennan SR, Poppi DP (2003) The development of a novel method to estimate microbial protein production in grazing Brahman crossbred cattle. Tropical and Subtropical Agroecosystems 3, 365-367.

Chen XB, Gomes MJ (1995) 'Estimation of microbial protein supply to sheep and cattle based on urinary excretion of purine derivatives: an overview of the technical details.' (International Feed Resources Unit, Rowett Research Institute: Bucksburn, Aberdeen, UK)

Chen XB, Ørskov ER, Hovell FDDeB (1990) Excretion of purine derivatives by ruminants: endogenous excretion, differences between cattle and sheep. British Journal of Nutrition 63, 121-129. doi: 10.1079/BJN19900097

FOSS TECATOR (2002a) Application sub-note ASN 3805. The determination of neutral detergent fibre using the fibercap system. FOSS TECATOR, Hoganas, Sweden.
FOSS TECATOR (2002b) Application sub-note ASN 3804. The determination of acid detergent fibre using the fibercap system. FOSS TECATOR, Hoganas, Sweden.

Fujihara T, Ørskov ER, Reeds PJ, Kyle DJ (1987) The effect of protein infusion on urinary excretion of purine derivatives in ruminants nourished by intragastric nutrition. Journal of Agricultural Science, Cambridge 109, 7-12.

Genstat Committee (2000) 'The guide to Genstat part 2: statistics.' (VSN International Ltd: Oxford, UK)

Giesecke VD, Balsliemke J, Sudekum K-H, Stangassinger M (1993) Plasma level, clearance and renal excretion of endogenous and ruminal purines in the bovine. Journal of Animal Physiology and Animal Nutrition 70, 180-189.

Gonzalez-Ronquillo M, Balcells J, Guada JA, Vicente F (2003) Purine derivative excretion in dairy cows: endogenous excretion and the effect of exogenous nucleic acid supply. Journal of Dairy Science 86, 1282-1291.

Liang JB, Pimpa O, Abdullah N, Jelan ZA, Nolan JV (1999) Estimation of rumen microbial protein production from urinary purine derivatives in zebu cattle and water buffalo. In 'Nuclear based technologies for estimating microbial protein supply in ruminant livestock. IAEA-TECDOC-1093, Vienna'. pp. 35-42. (International Atomic Energy Agency: Vienna)

McAllan AB, Smith RH (1973) Degradation of nucleic acids in the rumen. British Journal of Nutrition 29, 331-345. doi: 10.1079/BJN19730107

Ojeda A, Parra O, Balcells J, Belenguer A (2005) Urinary excretion of purine derivatives in Bos indicus $\times$ Bos taurus crossbred cattle. British Journal of Nutrition 93, 821-828. doi: 10.1079/BJN20051433

Orellana Boero P, Balcells J, Martín-Orúe SM, Liang JB, Guada JA (2001) Excretion of purine derivatives in cows: endogenous contribution and recovery of exogenous purine bases. Livestock Production Science 68, 243-250. doi: 10.1016/S03016226(00)00231-1

Osuji PO, Nsahlai IV, Khalili H (1996) Effect of fasting on the urinary excretion of nitrogen and purine derivatives by zebu (Bos indicus) crossbred (Bos indicus $\times$ Bos taurus) cattle. Journal of Applied Animal Research 10,39-47.

Pimpa O, Liang JB, Jelan ZA, Abdullah N (2001) Urinary excretion of duodenal purine derivatives in Kedah-Kelantan cattle. Animal Feed Science and Technology 92, 203-214. doi: 10.1016/S03778401(01)00259-0

SCA (Standing Committee on Agriculture) (1990) 'Feeding standards for Australian livestock: ruminants.' (CSIRO: Melbourne, Vic.)

Sweeney RA (1989) Generic combustion method for determination of crude protein in feeds. Journal - Association of Official Analytical Chemists 72, 770-774.

Vagnoni DB, Broderick GA, Clayton MK, Hatfield RD (1997) Excretion of purine derivatives by Holstein cows abomasally infused with incremental amounts of purines. Journal of Dairy Science $\mathbf{8 0}$, $1695-1702$.

Van Soest PJ (1963) Use of detergents in the analysis of fibrous feeds. II. A rapid method for the determination of fibre and lignin. Journal of the Association of Official Agricultural Chemists 46, 825-829.

Van Soest PJ, Wine RH (1967) Use of detergents in the analysis of fibrous feeds. IV. Determination of plant cell-wall constituents. Journal of the Association of Official Agricultural Chemists 50, 50-55.

Verbic J, Chen XB, Macleod NA, Ørskov ER (1990) Excretion of purine derivatives by ruminants: effect of microbial nucleic acid infusion on purine derivative excretion by steers. Journal of Agricultural Science, Cambridge 114, 243-248.

Manuscript received 25 May 2005, accepted 10 October 2005 